\title{
Home energy management systems and electric vehicles: challenges and opportunities
}

\author{
I. Junquera, J. García-Villalobos, I. Zamora, P. Eguía, J. I. San Martín \\ Department of Electrical Engineering - University of Basque Country - UPV/EHU \\ Alda. Urquijo, s/n, 48013 Bilbao (Spain) \\ e-mail: ijunquera001@ikasle.ehu.es
}

\begin{abstract}
Currently, residential users consume more electric energy during peak hours, mainly between $15 \mathrm{~h}$ and $22 \mathrm{~h}$ when the electricity prices are normally higher. Additionally, electric vehicle (EV) users tend to charge their vehicles at the same hours, increasing the impact on residential distribution networks. As a solution to these problems, a home energy management system (HEMS) can be used to decrease household energy demand at peak hours and reduce the impact of charging EVs in residential distribution networks. Additionally, HEMS can manage renewable energy sources and energy storage systems (ESS) to charge EVs in an efficient way.

The aim of this paper is to analyse the different aspects and concepts related to home energy usage and residential charging of EVs, as well as presenting the challenges and opportunities of HEMS together with vehicle-to-home (V2H) concept.
\end{abstract}

\section{Key words}

Home energy management systems vehicle to home, electric vehicle, demand response, electric appliance.

\section{Introduction}

EV sales (including both battery and plug-in hybrids) have increased by $70 \%$ between 2014 and 2015, with more than 550,000 vehicles sold worldwide in 2015 [1].

In fact, China has already overtaken the United States as the largest market for EVs, with up to 200,000 new registrations in 2015. Thus, these two markets have accounted for more than half of new EVs in the world.

Maintaining this overall growth rate will lead to a higher number of EVs than the target proposed by the Electric Vehicles Initiative (EVI) for 2020 [2]. Moreover, meeting all the targets set by several countries (Fig. 1), would result in a growth rate of $\mathrm{EV}$ sales around $60 \%$ a year between 2015 and 2020 [1].

One of the barriers to increase EV adoption rate is the range anxiety effect. But, the improvement in energy density of batteries reduces this problem. In 2008, energy density of the EV batteries was $60 \mathrm{Wh} / \mathrm{L}$. In 2015, energy density has reached $295 \mathrm{Wh} / \mathrm{L}$, improving by almost $500 \%$ [4].

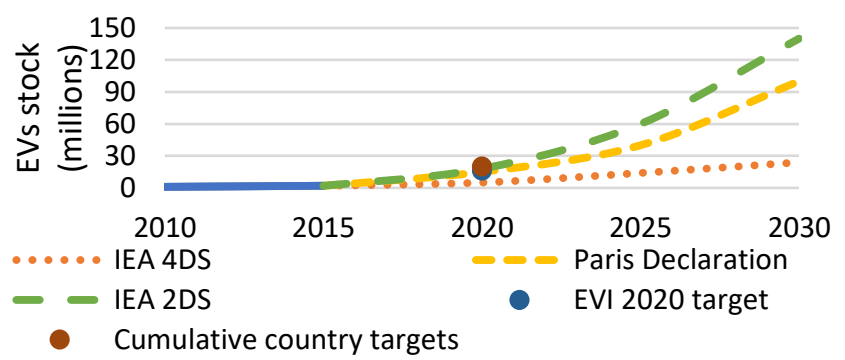

Fig. 1. Deployment scenarios for the stock of EVs up to 2030 [1], [2] and [3].

The goal of $400 \mathrm{Wh} / \mathrm{L}$ established by the US Department of Energy by 2022 requires further improvement of 36\%, to be reached over the next seven years, as shown in Fig. 2.

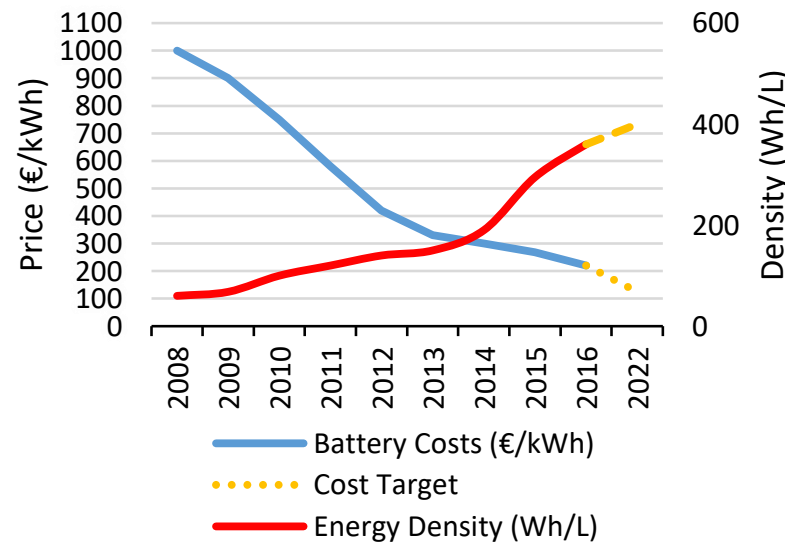

Fig. 2. Battery Energy Density and Price Evolution [1].

In this context, the batteries of EVs could be used to power households for certain periods of time. This concept is commonly referred as vehicle-to-home (V2H). Furthermore, EVs can be used to storage energy surpluses produced by local intermittent renewable power resources, such as solar or wind energy. Thus, it is necessary to develop a control system to efficiently integrate EVs and homes.

Besides, when designing a V2H system, domestic appliances have also a significant impact. Such devices can be classified into three general types, attending to their load profile, characteristics and behaviors: plain or 
smoothing, stochastic behavior and fixed programs. These three types of domestic appliances can be defined through a daily load profile (DLP), to show their functions and impact to the electric network. An example of a DLP is shown in Fig. 3, where the fixed program and the stochastic behavior types dominate the residential power consumption [5].

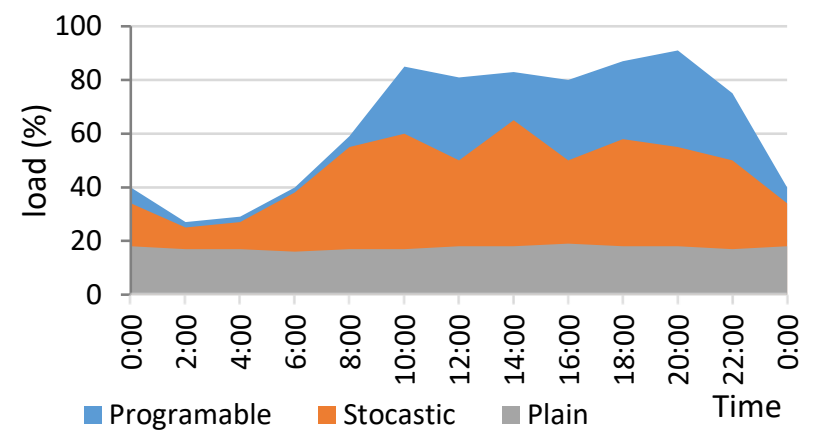

Fig. 3. Daily load profiles of home loads [5].

But different households will have different electrical appliances, operating characteristics and user preferences. Therefore, a large collection of measured data is needed in order to obtain statistical data and energy consumption of appliances.

The previous information about electric appliance usage and EV battery management preferences is fundamental for sizing the $\mathrm{V} 2 \mathrm{H}$ system and to integrate it into a HEMS.

The objective of the paper is to analyze concepts related to home energy usage and residential charging of EVs, as well as presenting the challenges and opportunities of HEMS to integrate V2H. The paper is organized as follows. Section 2 deals with residential charging of EVs and domestic appliances consumption characteristics. Section 3 reviews demand response concepts. Section 4 introduces the need for HEMS, discusses its applications and its challenges and opportunities. Finally, Section 5 concludes the paper.

\section{Residential charging of EV and domestic appliances}

European households are changing their habits. Residential electricity consumption of small appliances is growing, whereas large appliances are decreasing their consumption since the last twenty years [6]. In this context, EVs are a large appliance that can demand or provide energy to residential users. That means, EVs can change household`s electricity paradigm.

\subsection{Residential charging of EV}

In order to know the potential of $\mathrm{V} 2 \mathrm{H}$ technology, it is necessary to know if users prefer charging their EVs at home or, otherwise, at work or in a service station. A statistical study developed by Egbue and Long [7] analyzes the charging location preferences of students, faculty and staff at a technological university. The study has taken into account the views of 438 people of different gender, age, occupation, education and economic status. The figures shown in Fig. 4 allows to know that $70 \%$ of participants prefer to charge their EVs at home. In addition, [8] concludes that $82 \%$ frequency of charging is at home.

In this context, the concept $\mathrm{V} 2 \mathrm{H}$ can be considered in a real future. Also, Madina et al. [9] demonstrate that private home charging is likely to be the preferred option for EV users, who can charge at home.

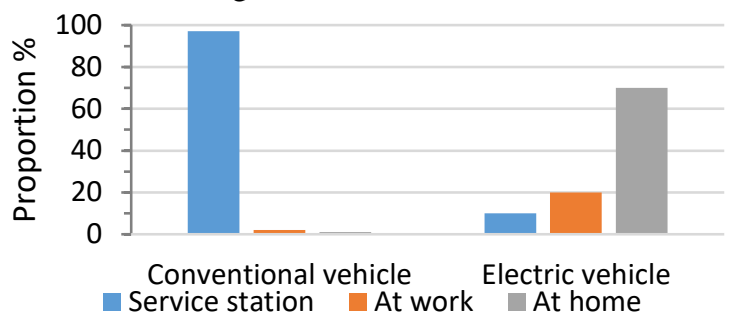

Fig. 4. Preference location for charging electric and conventional vehicles [9].

Furthermore, according to a Dutch report described in [10] and [11], it is estimated that most vehicles are available at home between 20:00h and 7:00h, and most people use their vehicles between 8:00h and 9:00h and between 16:00h and 17:00h. Therefore, EVs may be available as a storage system for 11 hours. During this time, EVs can be charged or discharged depending on the needs of the home and/or the supply system.

\subsection{Domestic Appliances}

The number of home appliances is rising, used more often and for longer periods of time. Also, many appliances have more functions or special features that require more energy consumption. Currently, electricity consumption in the residential sector is $29.71 \%$ of the total energy consumed in EU-28 [6]. Thus, household domestic appliances have grown in Europe by approximately $1.7 \%$ per year from 1970 to 2016. Besides, consumption per household has increased between 2014 and 2015 by $2.6 \%$ and consumption per person has increased by $2.8 \%$ [12].

In addition, appliances are classified as programmable and non-programmable. In this context, taking into account the users' preferences and timetable, more than $50 \%$ of the home appliances are programmable (Fig. 5) [6]. Besides, these programmable appliances can be classified in other two categories interruptible/uninterruptible and power variable/non-variable supply:

- In the first category, an interruptible appliance can be switched off by HEMS whenever necessary, to optimize energy costs. The appliance can be restarted when the energy price is lower.

- In the second category, a power variable appliance means that HEMS can decrease the power set point of this appliance. EV and ESS are examples of power variable appliances.

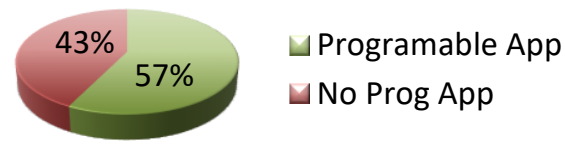

Fig. 5. Home appliances [6]. 


\section{Demand Response}

Demand response (DR) concept is defined as a change in the electricity consumption pattern to balance supply and demand. Additionally, demand response can reduce the cost of the electricity in the wholesale markets by reducing load demand at peak hours of the system.

Thus, a DR event is a period in which the load demand of the user could be restricted to relieve stress on the system. These events are encouraged or promoted by the electric utility and or by services offered by aggregators of retail customers (ARC). This DR operation depends on the electricity price, economic incentives or possible losses of electric system reliability.

In this context, home appliances could change their operating point depending on the electricity price and users' willingness, using DR signals as a special retail tariffs. Currently, there are three types of retail tariffs, according to the time period [13]:

- "Time of use pricing" (TOU). It has different fixed prices for a number of specified periods. It adapts quite well to the commercial and industrial consumption, but its use in the residential sector is limited.

- "Critical peak pricing" (CPP). It uses only one predetermined price or a table of prices applicable to certain periods, depending on the market conditions.

- "Real-time pricing" (RTP). It has a different price for each hour of the day. There are two types: "day in advance real-time pricing (DA-RTP)" that provides a pricing program for the next 24 hours, and "real-time (RT-RTP)" that provides hourly price for the next hour.

Thus, the user can chose among four types of program profiles to control the consumption [13].

- "Disconnectable". It provides a distributed control directly via radio, internet or another remote-control device. In addition, there is the possibility to disconnect specific loads or appliances without any warning.

- "Configurable". It is similar to the "disconnectable" program but it has the ability to control the power consumption of one or more appliances, for a specific period of time. The user can set the program when DR signals are received under certain conditions or restrictions. It is the most popular control and it largely reduces peak power demand.

- "Manual". It has no automatic control. Users perform manual changes in response to a discrete signal for a defined cost.

- "Behavioral". It is based on behavioral changes to produce a modification in electricity consumption. However, there are voluntary contributions that do not guarantee any performance payments in the electric bills. U.S. electric utilities offer home-energy data to their customers, which is another form of this type of program.

Therefore, DR will require the development of advanced measurement systems and distribution system planning tools. Thus, DR expect technology and staff investments to be developed. Furthermore, regulators and standards entities will play an important role.

\section{Home Energy Management System}

A home energy management system (HEMS) has the essential role to control appliances, such as air conditioners (ACs), energy storage systems (ESSs), EVs, renewable energy sources (RES) or heat pump water heaters (HPWHs), and automatically match their operation to the behaviour of the residential consumption, when the electricity price changes. Thus, the HEMS must learn the behaviour and the appropriate operation of controllable appliances.

In this context, Net Zero-energy houses (NZEHs) are being developed as consequence of this management. NZEHs are residential buildings that can generate as much on-site energy as they consume [14]. It can be pursued by combining energy efficient technologies, on-site power generation and smart energy-management appliances [15]. Furthermore, projects as [16] have already developed HEMS profile to monitor and control power consumption.

On the other hand, household peak demand can be increased with the residential charging of EVs. In this context, solar-wind powered generation systems interacting with energy storage systems (ESS) and EV batteries could be a solution. The charge of EVs could be offset by using an ESS system with RES. Moreover, if a real-time pricing option is set up, daily energy cost could be reduced, managing the hourly electricity price differences.

Therefore, the main objectives that are focused in the energy management systems, for residential networks are:

- Reduction of electric costs.

- Quality in the electricity supply.

- Security of electricity supply.

\subsection{Reduction of Electricity Bills}

Most recent studies, such as [17] and [18], have determined that one of the main objectives is to reduce energy costs for residential users. By optimizing the price and consumption profile in real time, or intervals of 5, 10 or 15 minutes, a reduction of the impacts produced by the charge of EVs at home is achieved. Consequently, a greater penetration will be possible in the residential networks.

There are several restrictions that should be met by a HEMS system. Firstly, the charge time and state of charge (SOC) that users want for their EVs at the end of the load. Secondly, the contracted power level. An increase in the contracted power limit and even a repowering of the home facilities could be avoided by an efficient energy management of charging the EV and the use of renewable energies. 
But, the reduction of electricity bills could impact on the level of comfort of users. This level of comfort is determined by the number of interruptions required to optimize the energy consumption and it can be adjusted by each user, depending on their preferences.

For the development of a manager device, three management levels could be taken into account:

- The first level has little or no management, only monitors energy parameters at home, like power demand, voltage and temperature.

- The second level is referred as smart level, which reduces energy costs without reducing user's comfort and according to user preferences.

- The last level is the most restrictive one, which reduces the cost at the minimum possible value and consequently, it reduces comfort levels at certain times.

The user is who sometimes chooses between these three management levels for a certain period of time. The HEMS will perform an optimal management according to the user's preferences and historical data.

For example, the research in [17] has shown a $20 \%$ reduction in household consumption by controlling voltage of appliances. Two different voltage control modes have been analyzed. The first one establishes a peak power limit by the user without restricting preferences. The other one, switches off the heater to optimize the energy consumption and to obtain a better voltage control.

Other authors [18], employ operational priorities settings of appliances, being used from the point of view of the user. The aim is to improve energy costs by managing controllable appliances, such as the heater. TOU (usage time) and IBR (inclining block rate) are incorporated to analyze the energy costs. The analysis shows that the incorporation of priorities into the HEMS can lead to a lower cost in the electricity bill. Additionally, the authors compare the two types of tariffs and demonstrate that the IBR option reduces costs more than the TOU tariff option. The domestic load demand curve becomes smoother, being more attractive to users and distribution system operators, as shown in Fig. 6.

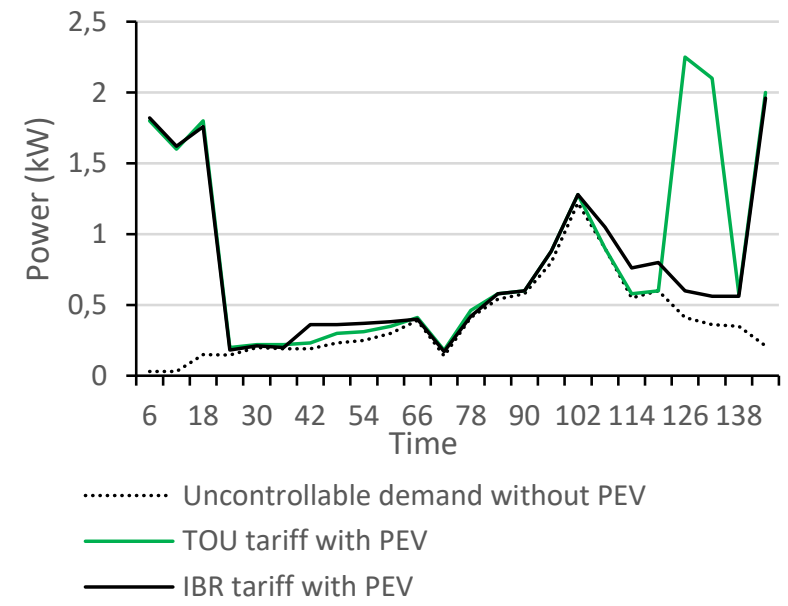

Fig. 6. Comparative among uncontrollable, TOU and IBR tariffs.

\subsection{Power Quality and Continuity of Supply}

Continuity of supply is especially important in isolated systems. Future smart homes with RES and ESS capacity could go off-grid when necessary. In [19] a centralized management system of a microgrid composed by batteries, photovoltaic panels (PV) and a fuel cell system (FC) is presented. By means of this management system with a master-slave approach, continuity of supply is maintained while the different energy resources and electricity prices are considered. In islanded mode, slave devices are configured as current sources and the battery converter switches to master mode to define the reference voltage and operating frequency of the system.

The main objective is to ensure continuity of supply. In addition, it has an impact on energy costs, maintenance and life extension of storage systems. An example of these systems is shown in Fig. 7, where a microgrid includes a PV system rated at $2.16 \mathrm{kWp}$, a FC rated at $1.2 \mathrm{~kW}$ and a ESS to deliver $1.5 \mathrm{~kW}$ during up to three hours. The microgrid is connected to a $220 \mathrm{~V} 60 \mathrm{~Hz}$ network.

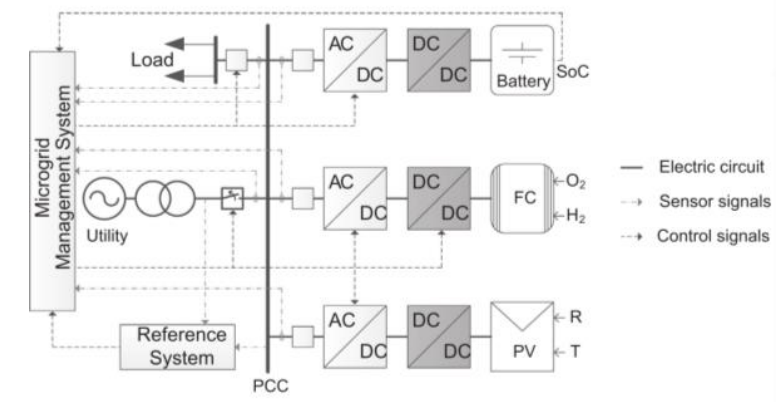

Fig. 7. Microgrid configuration.

Fig. 8 and Fig. 9 show the frequency drops and spikes when the microgrid changes to islanded mode and to grid connected mode later.

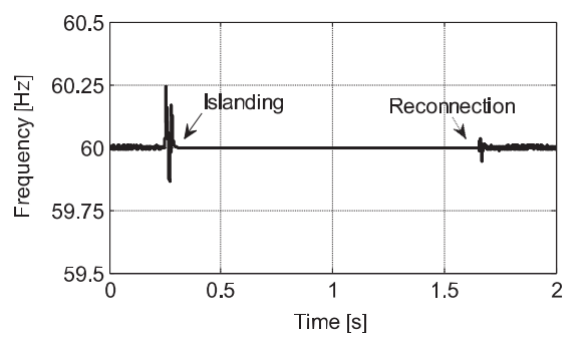

Fig. 8. Frequency pattern [19].

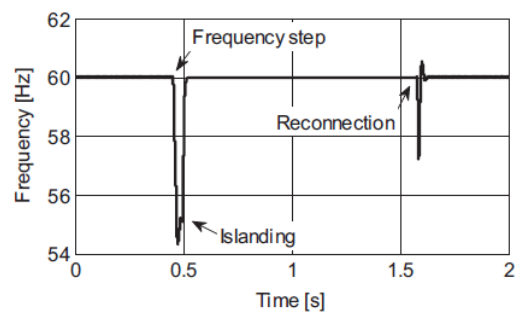

Fig. 9. Frequency variation in the microgrid [19].

Additionally, Fig. 10 shows the microgrid voltage during the transition between grid-connected and standalone modes, and the smooth transition between those two modes (Fig. 11). 


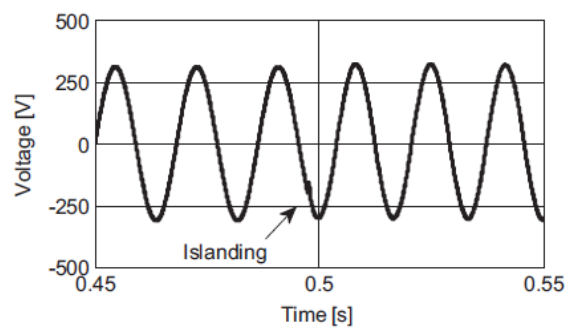

Fig. 10. Voltage across the microgrid during islanding [19].

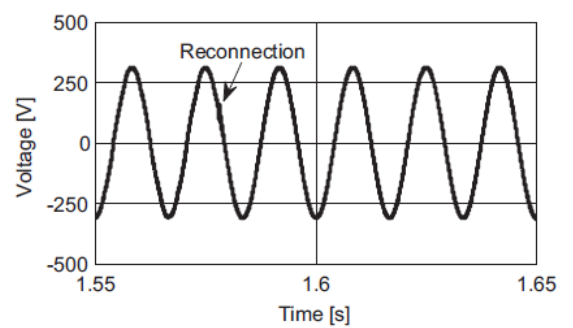

Fig. 11. Voltage across the microgrid during reconnection [19].

\subsection{Safety of Power Supply}

From the safety of power supply point of view, a power limit can be established in real time during a period of time, where the load demand is high [20]. Fig. 12 shows the established limits in a specific case, as well as the displacement of the load demand at home.

a)

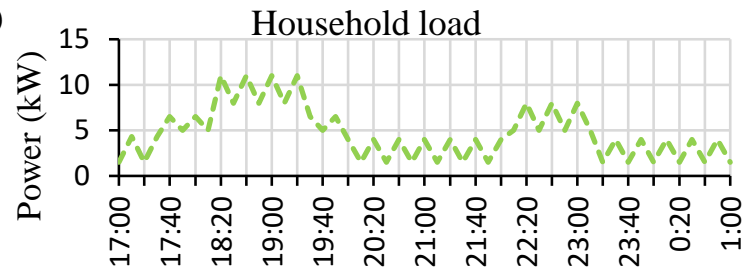

b)

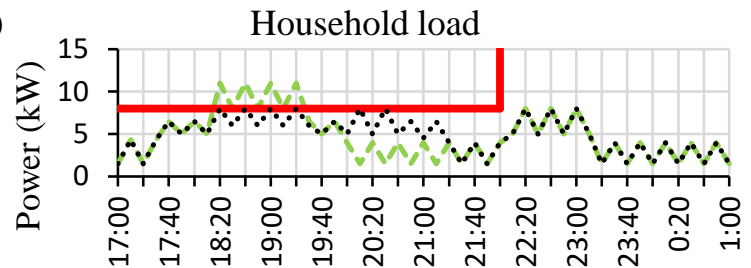

c)

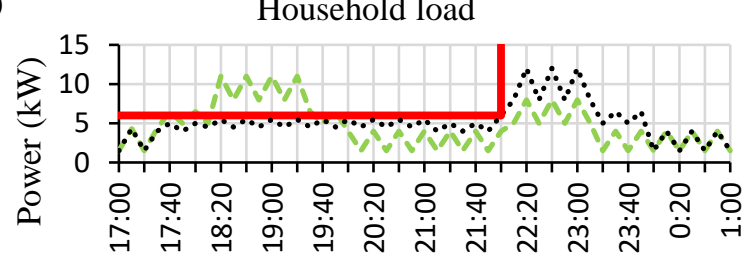

d)

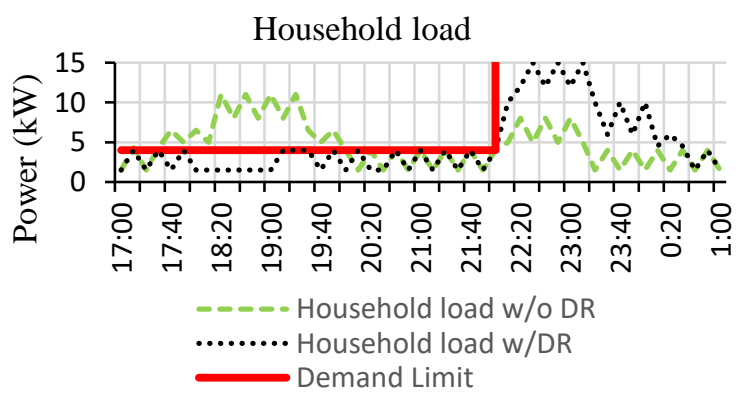

Fig. 12. Demand Response with a) no limit, b) $8 \mathrm{~kW}$ limit, c) $6 \mathrm{~kW}$ limit and d) 4kW limit [20].
Thus, the HEMS based in the DR algorithm [20] can be controlled actively and efficiently by setting demand limit in a specific way. Also, comfort level and appliances priority are taken into account. The analysis developed concludes that when setting a lower level of demand limit, users could have non-compliance or comfort violations. In addition, due to the low power level settings of the DR event, an increase of load demand could be generated after the peak period in order to compensate the unsatisfied load demand. Therefore, demand limits settings are defined by the DR events, taking into account user comfort level, as well as appliance priorities.

When the HEMS sets the priorities [20], the algorithm checks for comfort level violations. This HEMS has at its disposal loads signals, such as water heater temperature, room space temperature for the heating or cooling system, clothes dryer time of use and requested EV charging time. Using those data, the HEMS decides the priority of appliances based on the requested demand limit. Once it has been decided, the HEMS sends the control signals to the appliances. It can change the status of the appliance (ON/OFF or time of use). For example, if the household demand is higher than the limit, the comfort level will be affected due to the reduction of energy consumption. The HEMS will have to force ON-appliances to turn OFF, considering the appliance priority levels. Finally, if the household consumption is lower than the demand limit, no action is required and therefore, there is no decrease of comfort level.

In the case presented in [20] appliance priorities have been established as follows: Firstly, water heater (WH), secondly, cooling system or air conditioner (AC), the third is clothes dryer (CD) and, finally, EV charging is in the last priority status.

\subsection{Challenges and Opportunities}

The integration of EVs in local grids is one of the best ways to improve the environmental quality in cities from fossil-fuel pollution. But, they also can bring challenges and other opportunities to residential networks. That is why $\mathrm{V} 2 \mathrm{H}$ systems could be a solution for the integration of $\mathrm{EV}$ in residential networks.

Table I shows information about energy management challenges and opportunities in residential networks, when EVs and renewable energy are combined.

Table I. HEMS Challenges and Opportunities.

$\begin{array}{ll}\text { Challenges } & \text { - Use daily demand domestic profile } \\ & \text { - Control programmable appliances } \\ & \text { - Manage set-points of power variable } \\ \text { appliances } & \text { - Manage off/on time of interruptible } \\ \text { appliances } & \text { - Fit to battery type (lithium-ion, lead-acid or } \\ & \text { nickel-metal hydride) } \\ & \text { - Set battery capacity (available capacity, } \\ & \text { voltage, charging and discharging level } \\ & \text { currents and rated capacity) } \\ & \text { - Initial and final SOC }\end{array}$




\begin{tabular}{ll}
\hline - EV user habits \\
- Ton and Toff \\
- Electricity tariffs and prices \\
- Charge of EV at cheapest off-peak time \\
- Establish an isolated V2H system \\
- Ancillary services \\
\hline Opportunities & - Reactive power supply \\
- Reduction of electric costs \\
- Security of electricity supply \\
- Quality in the electricity supply \\
- Charging more than one EV \\
- Limit power in residential networks \\
- Power limit \\
- Reduction distribution losses \\
- Easy installation \\
- Energy storage systems can act as a home \\
backup generator and controllable loads \\
- Cooperation with other households in the \\
residential network \\
- Coordinated charge of EVs in a local \\
network \\
- Integration of RES \\
- Voltage levels maintenance
\end{tabular}

\section{Conclusion}

HEMS will play a relevant role in order to improve the efficiency, economy, reliability and quality of supply in smart homes. HEMS should manage the different appliances, energy resources and storage systems of a residential network. Therefore, it has to collect data from all these devices, grid operators and users to meet the expected functionalities. Additionally, HEMS must deal with several constrains, such as different tariffs and programs available in the market, different home appliances, timetables and EV charging necessities.

Consequently, the HEMS functions should be adjusted to the customer as reliable as possible. In that case, each customer will have to set the best profile in order to reduce electricity bills. Then the total current load and prices will be calculated locally. Each customer still needs to get the current information about the amount of electricity produced by RES and available in real time.

\section{Acknowledgement}

The work presented in this paper has been supported by the University of the Basque Country - UPV/EHU (PES-16/31) and The Basque Government (Ref. IT1083-16).

\section{References}

[1] I. E. A. International and E. Agency, "Global EV Outlook 2016 Electric Vehicles Initiative," IEA, vol. 1, p. 2, 2016.

[2] Clean Energy Ministerial, "Electric Vehicles Initiative (EVI). Thematic Area: ENERGY DEMAND.” pp. 1-2, 2016.

[3] N. Nuttall, "United Nations Framework Convention on Climate Change (UNFCCC)," Climate Change Newsroom, 2015. [Online]. Available: http://newsroom.unfccc.int/about/.

[4] U.S. DOE, "Revolution... Now: The Future Arrives for Five Clean Energy Technologies - 2015 Update," pp. 124, 2016.
C. Liu, K. T. Chau, D. Wu, and S. Gao, "Opportunities and Challenges of Vehicle-to-Home, Vehicle-toVehicle, and Vehicle-to-Grid Technologies," Proceedings of the IEEE, vol. 101. pp. 2409-2427, 2013.

[6] P. Bertoldi, B. Hirl, and N. Labanca, Energy Efficiency Status Report, Electricit. JRC Scientific and policy reports, 2012.

[7] O. Egbue and S. Long, "Barriers to widespread adoption of electric vehicles: An analysis of consumer attitudes and perceptions," Energy Policy, vol. 48, pp. 717-729, 2012.

[8] J. Smart and S. Schey, "Battery Electric Vehicle Driving and Charging Behavior Observed Early in The EV Project," SAE Int. J. Altern. Powertrains, vol. 1, no. 1, pp. 27-33, 2012.

[9] C. Madina, I. Zamora, and E. Zabala, "Methodology for assessing electric vehicle charging infrastructure business models," Energy Policy, vol. 89, pp. 284-293, 2016.

[10] K. Clement-Nyns, E. Haesen, and J. Driesen, "The Impact of Charging Plug-In Hybrid Electric Vehicles on a Residential Distribution Grid," IEEE Trans. Power

Syst., vol. 25, no. 1, pp. 371-380, Feb. 2010.

F. Berthold, B. Blunier, D. Bouquain, S. Williamson, and A. Miraoui, "PHEV control strategy including vehicle to home $(\mathrm{V} 2 \mathrm{H})$ and home to vehicle $(\mathrm{H} 2 \mathrm{~V})$ functionalities," in 2011 IEEE Vehicle Power and Propulsion Conference, 2011, pp. 1-6.

[12] Department for Bussiness Energy \& Industrial Stratergy, "Energy Consumption," Crown Copyr., vol. 1, pp. 1-44, 2016.

[13] P. Cappers, J. Macdonald, J. Page, and J. Potter, "Future Opportunities and Challenges with Using Demand Response as a Resource in Distribution System Operations and Planning Activities," Ernest orlando lawrence berkeley Natl. Lab., pp. 1-26, 2016.

[14] F. Harkouss, F. Fardoun, and P. Biwole, "Optimization of design parameters of a net zero energy home," 2016 3rd International Conference on Renewable Energies for Developing Countries (REDEC). IEEE, pp. 1-6, Jul2016.

[15] A. Bedir, B. Ozpineci, and J. E. Christian, "The impact of plug-in hybrid electric vehicle interaction with energy storage and solar panels on the grid for a zero energy house," Transm. Distrib. Conf. Expo. 2010 IEEE PES, pp. 7-12, 2010.

[16] L. TOYOTA Housing Corporation and Misawa Homes Co., "DENSO (Denso Corporation) Develops Home Energy Management System," http://www.globaldenso.com/en/newsreleases/11120701.html, 2011. [Online]. Available: https://www.denso.com/global/en/.

[17] O. Elma and U. S. Selamogullari, "A new home energy management algorithm with voltage control in a smart home environment," Energy, vol. 91, pp. 720-731, 2015.

[18] M. Rastegar, M. Fotuhi-Firuzabad, and H. Zareipour, "Home energy management incorporating operational priority of appliances," Int. J. Electr. Power Energy Syst., vol. 74, pp. 286-292, 2016.

[19] J. B. Almada, R. P. S. Leão, R. F. Sampaio, and G. C. Barroso, "A centralized and heuristic approach for energy management of an AC microgrid," Renew. Sustain. Energy Rev., vol. 60, pp. 1396-1404, Jul. 2016.

[20] M. Pipattanasomporn, M. Kuzlu, and S. Rahman, “An Algorithm for Intelligent Home Energy Management and Demand Response Analysis," IEEE Trans. Smart Grid, vol. 3, no. 4, pp. 2166-2173, 2012. 